\title{
Journalistic Metaphors as Attitudinal Markers of Sociopolitical Situation in Russia in Early 21st Century (Cognitive-Semantic Aspect)
}

\author{
Elena E. Kotsova ${ }^{1}$, Tatyana A. Sidorova ${ }^{1}$, Elvira N. Akimova, ${ }^{2, *}$, Nataliya E. Petrova ${ }^{3}$, \\ Konstantin V. Skvortsov ${ }^{4}$, Irina S. Karabulatova ${ }^{5}$ \\ ${ }^{I}$ Honorary Worker of Higher Professional Education of the Russian Federation, Russian Language and Speech \\ Culture Department, Northern (Arctic) Federal University named after M.V. Lomonosov, Arkhangelsk, Russia \\ ${ }^{2}$ Department of Russian Philology and Cross Cultural Communication, Pushkin State Russian Language Institute, \\ Moscow, Russia \\ ${ }^{3}$ Department of Russian Language and Speech Culture, Minin Nizhny Novgorod State Pedagogical University (Minin \\ University), Department of Russian Language and Culture of Speech, Nizhny Novgorod, Russia \\ ${ }^{4}$ Russian University of Transport, Moscow, Russia \\ ${ }^{5}$ Department of Foreign Languages of the Philological Faculty Peoples' Friendship University of Russia (RUDN- \\ university), Moscow, Russia \\ ${ }^{*}$ Corresponding author. Email: akimovaen@mail.ru
}

\begin{abstract}
The relevance of the study is conditioned by the growing interest in the analysis of the formation of journalistic metaphors as attitudinal markers, means of cognitive and evocative-stylistic evaluation, which makes it possible to keep a close watch on the way the Russian mindset is changing. The main purpose of the study is to identify some cognitive-semantic aspects of journalistic metaphors in contemporary periodicals texts and Internet communication. The main study method is cognitive-semantic analysis of the most important models according to which journalistic metaphors as elements of theory for research into contemporary journalistic discourse are being formed.

The present study identifies key journalistic metaphors as evaluative markers of the sociopolitical situation in Russia in the 2010s.

These are not metaphors-clichés that are of interest, but occasional tropes reflecting most vividly the response of politicians, political analysts, public people to socio-political events in contemporary Russia, such as sanctions, retirement-age increase, coronavirus pandemic and self-isolation of the Russian people.

The study identifies cognitive mechanisms and methods of objectification of metaphoric models (donor domains and recipient domains). The most fruitful topical donor domains as sources of journalistic metaphors are highlighted. It is proved that the cognitive-semantic special aspects of metaphors are conditioned by the belief systems and worldviews of the addressers. The role of journalistic metaphors as means of influencing the addressee and a way of expressing the modal-evaluative attitude of the addresser to one or another reality is determined. The relationship of journalistic metaphors with the socio-political situation in Russia is established.

Keywords: journalistic metaphors, cognitive-sematic models of metaphors, conceptual donor domains and recipient domains, media texts and Internet communications on sociopolitical issues

\section{INTRODUCTION}

As one of the means of creating expression, metaphors more quickly, flexibly and vividly reflect the socio-

political processes taking place in modern Russian society. The widespread use of metaphors in journalistic texts is a necessary condition for the functioning of the language of mass media, and contributes to the implementation of the most important functions of journalism - persuasion and emotional impact $[1,2]$.
\end{abstract}


The relevance of the study of journalistic metaphors lies in the significant role of the media in society, the need to study metaphors as cognitive models. The choice of modern journalistic metaphors as the object of research is due to the activation of their role in understanding events in the socio-political and financial-economic life of the country at the beginning of the XXI century. The relevance of the analysis of the formation of these metaphors as a means of cognitive and expressive-stylistic assessment allows us to track the changing mentality in Russia at the turn of the twentieth and XXI centuries. The main goal of this research is to identify the cognitive and semantic features of journalistic metaphors in the texts of modern periodicals and Internet communication that reflect socio - political events in Russia in the 2010s. In the course of the research, a selection of key metaphors was made as evaluative markers of the socio-political situation in Russia at the beginning of the XXI century, and the analysis of the most relevant cognitive-sematinical models for the formation of publicistic metaphors (the ratio of donor and recipient spheres) was carried out.

The object of research is journalistic metaphors in the texts of mass media and Internet communication of the last decade. The subject of the research is the cognitivesemantic and functional features of journalistic metaphors as markers for understanding and evaluating the sociopolitical and financial-economic situation in Russia at the beginning of the XXI century. The novelty of the research is due not only to the cognitive-semantic approach to the analysis of modern metaphors, but also to the source of the selected material for analysis - the texts of periodicals and Internet communications of the last decade. The authors offer an analysis of journalistic metaphors as evaluative markers of the most significant events in Russia during this period, namely: sanctions against the participation of Russian athletes in the 2018 winter Olympics, pension reform, the coronavirus pandemic, and self-isolation of Russians.

\section{LITERATURE REVIEW}

A review of the scientific literature shows that the method of studying metaphors at the present stage has a multiaspect orientation. Metaphors are actively studied by linguists not only in semantic, functional-stylistic, linguistic-rhetorical, axiological, psycholinguistic, communicative-pragmatic, but also in cognitive aspects.

From the standpoint of the cognitive approach that was developed in linguistics at the end of the twentieth century, figurative meanings, such as metaphor and metonymy, serve as the main sources of information about the organization of human thinking at the level of secondary nomination of reality phenomena.

The analysis of the cognitive metaphor serves as a means of identifying existing in the national consciousness ideas about the current socio-political situation in Russia, including the activities of higher state authorities, political parties and other public organizations, the life of the regions, the state of the financial system, industry, agriculture, etc. [2].

The works of A. P. Chudinov [3-5] and E. V. Budaev [68] devoted to the cognitive-semantic analysis and classification of journalistic metaphors, depending on the subject of their donor spheres should be particularly noted.

The study of metaphors from a cognitive and semantic point of view is related to the concepts of metaphorical model, sphere-donor, sphere-recipient. At the same time, the setting for the interaction of donor and recipient spheres is updated. It is recognized that it is impossible to study the journalistic metaphor, evaluate its semantic and functional-stylistic role without studying its sources, those thematic areas-donors, the transfer of lexemes (sound shells of words) from which allows us to understand and figuratively evaluate the socio-political events that occur in modern Russia at the beginning of the XXI century. The question of cognitive-semantic models of metaphors, or the grounds for transferring names from one conceptual domain to another, is still not fully resolved. How do associative connections of identified phenomena arise? How is the "filling" of certain thematic areas-recipients of publicistic metaphors carried out? These problems have not yet been resolved.

Visual and expressive means, primarily metaphors, are the main ways of understanding and describing significant socio-political and economic phenomena for Russians [9]. The subject of attention of cognitive scientists is metaphors in the sphere of Economics, the Internet in the speech of computer users, social networks in the media discourse $[10,11]$. As our observations on publicistic texts on financial and economic topics and the results of research on the professional vocabulary of economists and financiers show, metaphors in these areas immediately have a nominative orientation or quickly become desemanized, become cliches in the structure of composite terms (paralyzed markets, parent company, dismantling (undermining) economy, investment inflow, economic take-off, price jump, industrial development, etc.).

This study examines the expressive journalistic metaphors that characterize the most significant socio-political events of the 2010s in Russia. In the analysis of metaphorical models, it is particularly important to identify the most relevant thematic areas-donors and recipients-in the formation of such metaphors [2].

\section{METHODOLOGY}

The theoretical basis of the research is the works of Russian and foreign linguists devoted to the problems of metaphorization in different discourses. These are the works of N. D. Arutyunova [12, 13], J. Lakoff [14], V. G. Gak [15], A. N. Baranov [16], E. S. Kubryakova [17], V. P. Moskvin [18, 19], V. N. Telia [20], G. N. Sklyarevskaya [21], V. K. Kharchenko [22] and other. 
The study of metaphors in modern linguistics is multidimensional: the semantics, cognitive nature, semantic models of metaphors, their functions and stylistic possibilities are studied on the material of different parts of speech and discourses.

The Central principle of the research is anthropocentric, which provides an analysis of the language features of metaphors in close connection with the communicative situation. The cognitive-semantic approach to the analysis of journalistic metaphors allows us to understand the addressee's value attitudes, presuppositions, and basic concepts. From the point of view of cognitive linguistics, the metaphorical model objectifies mental schemes of human consciousness and forms a new idea about the world object, event, situation. See, for example, research $[23,24]$. Since metaphors are interpreted in context, the paper implements the concept of combinatorial logic using contextual research [25], as well as the idea of categorization mobility under the influence of various contexts [2, 21, 24, 26].

The authors of journalistic texts do not so much inform the mass reader, as Express their own attitude to the realities of reality, socio-political events, evaluate them based on their position, experience and observations, acting as equal partners in communication, reflecting the dual language consciousness as representatives of Russian society. Therefore the subject of the research is publicistic metaphors that objectify the perception and representation of the socio-political situation in modern Russia.

The material for the research is the texts of mass media and Internet communications of the 2010s-2020s, reflecting the current socio-political and financialeconomic situation in Russia. These are separate issues of Central and regional Newspapers (Argumenty I Fakty, Sobesednik, Komsomolskaya Pravda, Rossiyskaya Gazeta, Parlamentskaya Gazeta, Vedomosti, Vzglyad, Nezavisimaya Gazeta, Tomorrow, Izvestia, Arkhangelsk, Express Gazeta), including official websites of Newspapers and news agencies, and Internet portals (sobesednik.ru, arh.mk.ru, aif.ru, rg.ru, eg.ru, rvs.su, Solidarity. Central trade Union newspaper, interregional Internet magazine "7x7", independent Internet portal Odintsovo-info, etc.), blog materials, as well as statements of participants of TV debates on socio-political issues on Central TV channels. A large body of data allowed the use of a case-oriented approach for the study of metaphors.

\section{ANALYSIS AND RESULTS}

The journalistic texts we study are United by a common socio-political theme that reflects the most significant, resonant events in the life of Russia in the second decade of the XXI century, as well as the intentions of the authors of these texts aimed at understanding and evaluating these events [27].

In the course of analyzing journalistic metaphors in the texts of modern periodicals, we identified the socio- political events of the 2010 s, objectified in metaphors [28, 29]. "A metaphorical model is an existing or developing in the minds of native speakers scheme of communication between two conceptual spheres, which can be represented by a certain formula: «X is $\mathrm{Y} »[30]$.

The analysis of semantic models of journalistic metaphors has a cognitive orientation and takes into account the interaction of donor spheres and recipient spheres, when one cognitive model covers a certain set of lexemes that, according to this scheme, connect the final and initial spheres, or the recipient sphere and the donor sphere.

The analysis of journalistic metaphors selected from the texts of individual issues of Central and regional media and Internet communication in the 2010s revealed the dominant conceptual areas-donors as nominative sources for metaphorical models, as well as the recipient areas, which are most actively replenished with journalistic metaphors.

\subsection{Conceptual spheres-donors of publicistic metaphors}

1. As a result of cognitive analysis, the most productive semantic models of internal metaphors in the texts of modern periodicals of the 2010 s were identified. The main recipient area, within which publicistic metaphors are formed and actively used, is the text of socio-political and financial-economic topics. The main donor areas for creating such metaphors are:

2. Specific physical phenomena (objects, including artifacts, actions, signs related to different thematic areas). This is a broad donor sphere that allows further categorization of metaphors into subgroups that characterize socio-political, financial and economic phenomena, human relations, business, sports, music, fashion, etc.

3. Metaphors that go back to a specific subject vocabulary are characterized by a high degree of occasionality. Cf.: 1) now Ukraine least needs "gasoline", a bonfire of contradictions; 2) Rather the opposite - the city and the island protected themselves from the Maidan revolutionaries, smelling of square borscht and American cookies; 3) We are all at different levels of spiritual development. Therefore, many people need a teacher, a priest, an assistant. Need crutches in the form of rites, chants, rituals.

4. The sphere of medicine, anatomy and physiology (names of diseases, diagnoses, medical procedures and tools, the physiological state of patients, etc.): 1) I Believe that the deepest coma of the Minsk process is over; 2) $\mathrm{He}$ noted that the Crimean bridge is more than a structure over the Kerch Strait. This, Borozdin added, is the most important artery for Kerch; 3) If I wrote what I feel, and people react to it this way, it means that I hit a nerve; 3) it is not difficult to guess that these regions will become a real headache for the authorities; 4) Power under the influence of mutagens (the influence of Western all- 
consuming capitalist ideology) is reborn into a cancer, begins to feed from the People through social institutions"; 5) $\langle\ldots\rangle$ under the guise of this mass intoxication, they are rushing to legalize what is essentially anti-national; 6) This February gave Muscovites along with the snow collapse a fairy tale; 7) Humanity, as a powerful information carrier, for the first time faced a total non-infectious pandemic of fear

5. Along with metaphors-cliches (artery, hit a nerve, headache), such fresh, expressive metaphors from the sphere of medicine as the deepest coma of the Minsk process, the pandemic of fear also appear in the journalistic discourse.

6. Productive areas-donors of journalistic metaphors are the vocabulary of the thematic group " Nature, its phenomena. Plant and animal world". SR.: 1) the Rest of the poachers here will be seized by the pike gills; 2 ) the Discussion on how to protect children from virtual threats and not turn the Internet jungle into a reserve, where you just can't get there, unfolded today in the regional parliaments of Russia.

\subsection{The conceptual sphere-recipients}

1. Content analysis of journalistic texts of the 2010s revealed a few socially significant events in the life of Russia during this period, which were considered as conceptual areas-recipients for the formation of journalistic metaphors.

2. The winter Olympics (2018). the description of this bleak event for Russians, associated with a fabricated doping scandal, is dominated by metaphors of a specific subject "origin". They Express the negative consequences of the sanctions imposed on Russian athletes on the eve of the 2018 winter Olympics. (cut, passing through a sieve, broom swept, thrown, caught in a meat grinder, etc.). Wed.: 1) the Command cut, missing through a sieve of obscure criteria, ignoring the court's decision, which found no evidence of doping guilt in humans; 2) does it Occur to him that the anti-doping broom swept clean athletes, stars who can decorate the Games with their presence?; 3) I am full of sympathy for our athletes, they were crazy chopper; 4) Ana and 52 people just «vykinuli» the list of invitees to the Olympics; 5) 168 people from our team who went through all rugiada who need ducttape to seal and a scarf to cover up the prohibited logo and received approval for a trip to Pyeongchang; 6) meanwhile, the ideological machine, without parsing the road, rushes straight to the school, leaving around the poisonous exhaust of hatred. The expression of metaphors is enhanced by the reception of semantic applications or the expanded, occasional nature of the metaphor itself.

3. Elections of the President of Russia (2018): 1) Against this background, it is strange to hear from Grudinin stories about the socialist district, which he allegedly built in the Lenin state farm; 2) this will be the beginning of a sluggish but dramatic political decline of Putin as a political institution and a guarantor of the stability of the system; 3) the Second goal-elections are empty and uninteresting if they do not have a liberal stream.

4. The coronavirus Pandemic and self-isolation of Russians (2020). in assessing the situation with statistics of the coronavirus pandemic in Russia, dry metaphors are most often used-stamps (decrease, increase. peak). Against this background, more recent are the metaphors from the professional speech of doctors (epidemic plateau, red zone). Wed..: 1) according to the forecast of mathematicians and biologists, the coronavirus epidemic in Russia will reach the plateau in 10-14 days. $<\ldots>$ The epidemic plateau is the period that occurs after the peak of morbidity is reached. "Reaching the plateau occurs $\langle\ldots\rangle$ when the daily increase is approximately the same number of people. $<\ldots>$ After this, the epidemic begins to decline. The other block of metaphors is more expressive and occasional. These metaphors characterize the assessment of the quality of monitoring of the pandemic and control over the self-isolation of the population by the authorities: 1) Laws are stamped on the move in combat conditions, in three readings in one day - how to intimidate people and close their homes, even more restrict their rights. Although before that, for example, the wealth tax cannot be accepted for several years; 2) this is an electronic concentration camp, in which we are confidently driven on the introduction of digital passes in certain regions in conditions of self-isolation. Occasional word formation metaphors are also formed: CHARONovirus, quarantine+canicularies (this Latin word "canicula" entered the Russian language to indicate a period of rest in school, work. In Ancient Rome, the period of summer heat coincided with the beginning of the morning visibility of Sirius, called Canicula ("little dog"). These days were called "dies caniculares" - "dog days" (from July 22 to August 23), considered the time of summer vacation); Isolandia (insulation + finale to designate the country - land), etc.

In the derivative Charonovirus, the conceptual sphere of MYTH, which interacts with the sphere of MEDICINE, is determined not only by language (the phonetic appearance of the mythical name Charon correlates associatively with the phonetic appearance of the word "crown"), but also by culture. At the same time, the concept of "death" dominates the consciousness. Graphic highlighting of the name of a mythical character (capitalization technique) actualizes the situation behind the name and is identified with the situation of the pandemic.

5. In connection with the pandemic, such an urgent problem of the current socio-political situation in Russia as social inequality in the income of Russians, the growth of poverty, unemployment, and against this background, the lack of real assistance from the Russian oligarchs has worsened. The most frequent in assessing this situation are metaphors-stamps stratification of society, the gap between rich and poor, the war with the pandemic, etc.). there are Also more expressive metaphors of negative assessment of the social stratification of Russians (sorting 
of citizens, pocket TV channels, crooked statistics, PR dust, budget oligarchy). SR.: 1) but now, in the conditions of the epidemic, will we not talk about sorting citizens: the poor - natural selection, plantain and prayer, and the rich-a separate ward and a personal ventilator?; 2) in Russia, real help from billionaires has been replaced with PR-dust. Many words, little specifics. <...> Then everyone will understand how and who invested in the war against the pandemic; 3) $\langle\ldots>$ after all, neither pocket TV channels nor crooked statistics will save you from epidemics; 4) Budget oligarchy, which grew up on two pillars-the ability to independently manage salaries within their institutions and access to public procurement $\langle\ldots\rangle$. 6 . Pension reform. The increase in the retirement age in the summer of 2018, which was legalized by the President of Russia on October 3, 2018, caused a particularly sharp and emotional reaction among Russians. The journalistic metaphors that characterize this event will be the main focus of this article. "Pension" metaphors - metaphors in journalistic texts, periodicals and online publications on the response of the journalists, political analysts, politicians, economists and other public figures on the government's decision to raise the retirement age of Russians at five years of age (women -60 years, men 65 years).

The empirical base of the research on pension reform was made up of texts from Internet sources, where arguments were made against its adoption. Unfortunately, the official media only "zombified" the population with " mantras "that the" mission " of the reform is to increase the level of pensions, that there is no other way to replenish the Pension Fund, as there is no increase in the retirement age by five years. Against the background of "hysteria on Federal TV channels" in this "TV gum" there was "no meaningful discussion". As a result, the protest moods of Russians, which were almost not reported on official TV channels, appeared in the network space.

In the texts of Internet publications devoted to this issue, an abundance of metaphors was noted, including occasional tropes with a high degree of negative expression, up to sarcasm (usual metaphors are further highlighted in text fragments in italics, occasional - in bold italics).

The analysis of texts allowed us to identify the main objects of evaluative metaphorization in the characteristic of this social phenomenon:

1. Assessment of the pension reform and its consequences for the people. The most frequent in its characteristic for Russians were the metaphors of genocide, cannibalism, (pension) robbery, default. SR.: "raising the retirement age is the genocide of the village in its purest form"; "reform of pension cannibalism"," the virus of pension genocide "; brazen robbery of the people; pension default the meat grinder of exploitation; a wellaimed shot of power into the soul and heart of the people, a harbinger of the demographic abyss! (slogans at protest rallies in Moscow); about power: not a shot in the leg, it's a political shot in the temple; the stranglehold; programming of social cataclysm, the line to destroy the Russian people, the long-term program of genocide, etc.

2. Assessment of power structures and their actions to promote reform. SR.: 1) how to break the established, hardened power structures, intertwined with the tentacles of corruption, glued together by mutual compromising materials, stupefied by impunity and fattened by the robbery of their own people? How can we avoid crossing the fine line between radical perestroika and a war for power? 2) " Masks are reset. Pathetic speeches about development and breakthrough turned out to be a bluff the country has a broken trough. Around the trough there was a violent stampede, and "effective managers" first of all decided to sacrifice the welfare of the elderly. 3) the Father-President clearly explains to his children with fatigue in his eyes why it is impossible to do without raising the retirement age. <...> The "caramels" promised in the address will certainly reduce the degree of discontent of the population.

The main sources of "pension" metaphors are such thematic areas as" Disease, physiological state "(cancer, mutagens, intoxication, biological dislocation, hangover)," Violence, conflict " (war, struggle, shooting, robbery, genocide, as well as the sphere of artifacts (caramels from Putin, meat grinder).

Often pension "initiatives" of the government are compared to a farce, tragedy, dystopia, madhouse, performance, with the actions of biorobots, trained animals. SR.:

1) the world of Kafka and Orwell, built in Russia after 1991, continues to throw surprises to people <...> pension robbery of Russians will bring losses, not revenues to the budget. But if this is all unprofitable, why did they need to rock the Titanic so powerfully?

2) I have nothing to say as an economist. Because this is a performance. $<\ldots>$ The government, from my point of view, executes a certain command. Russian officials and deputies receive certain control signals "from above" and, like biorobots, start running, fussing, performing, and then pressing buttons. It's like a pack of trained hamsters. <...> They understand that it is necessary to "correctly" press the button. And if you" incorrectly " click, then you will find yourself on the street with things.

3) What kind of madhouse do we live in? $\langle\ldots\rangle$ we are mired in a criminal-capitalist swamp <...> What is happening now with the pension reform looks like both a farce and a tragedy ...it is possible and necessary to resist all negative processes in the fight by all constitutional methods, until the thread is torn off. And God grant that the elite scoundrels do not once again disrupt it.

In the following text fragment of the opposition politician S. Mitrofanov, the key occasional metaphor of the Pharaonic becomes expanded, grows to the level of the whole text, becoming a powerful means of personal assessment of the situation. SR.: $\langle\ldots\rangle$ the Pharaonic sislibs (system liberals) suddenly come to mind... And let " our " row to death! First, we will plug the holes in the Pharaoh's pension Fund $\langle\ldots\rangle$, and second, there will be no 
idle staggers on the upper deck, no unnecessary fuss, and no one will fall overboard drunk. For not every man in Russia lives to the cherished 65 . <...> As the pressSecretary of "Paranete" Misha Leontiev <...> fully supported the reform. Idleness is not originally characteristic of the oarsmen of our galley, $<\ldots>$ in their rowing nature to row exactly as long as health allows. Specially herded into the Pharaoh's ether, elderly female slaves told the slave youth that only now they $\langle\ldots\rangle$ understood the beauty of the profession of rowing on a galley $\langle\ldots\rangle$ And the more able-bodied slaves chained to the oars, and the less idle passengers, on the contrary, the more worthy will be the life of those whose personal biological dislocation will allow them to accidentally survive in this total meat grinder of exploitation" .

In this fragment, the entire situation with pension reform is metaphorized. the "Pharaonic" theme "forms a kind of conceptual blanket that is thrown over the analyzed social phenomenon" [31].

The dominance of expressive journalistic metaphors in the characterization of complex, crisis situations in the life of the country reflects the leading-negative-intention of evaluative metaphors in journalistic texts.

\section{DISCUSSION}

The use of metaphors that characterize the current sociopolitical situation in Russia stimulates the attention and interest of readers to statements on a relevant topic.

Cognitive-semantic analysis of metaphorical models has shown that the most productive are not external, but internal metaphors, in particular, the transfer of names from the sphere of specific subject vocabulary (especially artifacts), medicine, nature, and its phenomena to the sphere of socio-political events. Not only metaphorscliches are actively used, especially in the sphere of financial and economic vocabulary (the fall of the ruble, economic growth, currency corridor), but occasional tropes are created (electronic concentration camps, antidoping broom, the meat grinder of exploitation). Such metaphors allow us to see socio-cultural and political situations through the prism of everyday life, which is typical for the Russian mentality as a whole.

Active areas-donors of modern journalistic metaphors are also the thematic areas " Medicine "(the deepest coma of the Minsk process, the pandemic of fear)," Nature, its phenomena, the Plant and animal world " (the jungle of the Internet).

The main principle of creating and using bright, emotionally expressive metaphors is the indifferent attitude of politicians, economists and journalists to a particular acute crisis situation in the country.

Thus, in the course of the research, the donor and recipient spheres were identified within the semantic models of journalistic metaphors. Priority conceptual areas and the conditionality of their choice are noted. The mechanism of mental operations in the process of forming metaphors is shown. Attention is drawn to the fact that Russia as a whole is represented in the images of a theater, a mental hospital (madhouse), a swamp, which marks a situation of spiritual, and not only economic crisis. The cognitive dominant "relations of power and people" is brought to the fore, and these relations are represented by the historical nominations "pharaohs - slaves (rowers on galleys)", which emphasize the social stratification of society and the attitude of power structures to the people. A pragmatic approach is being implemented: "The government should take care of the people." The opposition " father-children "(about the relationship between the President and the Russians) actualizes the image of Stalin ("father of peoples"), which conceptualizes the idea of totalitarianism and cruelty. But in General, this opposition actualizes the concept of FAMILY, which remains the most important for Russians. It should be noted that the most relevant conceptual areas of interaction in the formation of metaphors are those that cause associations with severe illness or death. The idea of the absurdity of the government's activity (the "Titanic" of stability) is widely spread.

Journalistic metaphors should be considered a new discursive practice that reflects sociocultural practice. Cognitive-semantic features of the investigated metaphors of determinate factors such as language consciousness, cognitive consciousness, culture, history, Russian language mentality, value orientations and personal meaning senders dominant discourse

\section{CONCLUSION}

As shown by the research material, further study of journalistic metaphors in texts that characterize the realities and events of modern Russian life is promising from the standpoint of a cognitive approach. The cognitive-semantic analysis of metaphors in the texts of the modern media space allowed us to identify the most productive metaphorical models based on the ratio of donor spheres of secondary nominations and recipient spheres, which are most actively replenished with metaphors that characterize events in the socio-political life of Russia. We believe that this analysis will allow us to identify the corpus of modern journalistic metaphors with "binding" to certain socio-political events (recipient spheres), differentiate metaphors-cliches and metaphorsoccasionalisms within these spheres.

The analysis of the most relevant cognitive-sematinical models of publicistic metaphors formation, the ratio of donor spheres and recipient spheres allows us to consider the results of such research as a fragment of the theory of modern publicistic discourse.

Observations on journalistic metaphors as evaluative markers of the socio-political situation in Russia at the beginning of the XXI century in the modern media space, on cognitive-semantic models of metaphors in the texts of socio-political issues allow us to judge the specifics of the 
language consciousness of modern Russian publicists, which is very important when describing the language personality as a whole, to identify the features of their language as discursive personalities. This is relevant not only for discursology, but also for axiological linguistics, psycholinguistics, sociolinguistics, and the theory of linguistics. It is promising to analyze the processes of modeling metaphors and identify trends in the development of models, determining the features that are most significant for the addressees. As we have shown above, behind the mental operations in forming metaphors are various structures of knowledge that need to be decoded and further categorized. Some conceptual areas that are waiting for research have also been ignored. For example, the fields of EDUCATION, SCIENCE, ART, etc.

\section{ACKNOWLEDGMENT}

This study has been completed with the help of the financial support granted by the Ministry of Education and Science of the Russian Federation under the Program of Increasing the Competitiveness of PFUR "5-100" among the world's leading scientific and educational center's for 2016-2020.

\section{REFERENCES}

[1] E.V. Kakorina, Internet Metaphors in the speech of computer users, in: Man and language in the communicative space: collection of scientific articles. Krasnoyarsk, Siberian Federal University, 2013, Pp. 145-150.

[2] I.S. Karabulatova, M.S. Vykhrystyuk, N.G. Dolzhenko, E.I. Mychko, E.V. Potmenskaya, The Use of Stable Expressions in Modern Economic Discourse as an Emotional Increase in the Potential Impact on Purchasing Power, Space and culture, India 7(4) (2020) 283-292. DOI: https://doi.org/10.20896/saci.v7i4.488

[3] A.P. Chudinov, Russia in the metaphorical mirror: a Cognitive study of political metaphor (1991-2000): a monograph, Ural State Pedagogical University, 2001, $238 \mathrm{p}$.

[4] A.P. Chudinov, Metaphorical mosaic in modern political communication: a monograph, Ural State Pedagogical University, 2003, 248 p.

[5] A.P. Chudinov, Essays on modern political metaphorology: a monograph, USPU, 2013, 176 p.
[6] E.V. Budaev, A.P. Chudinov, Metaphor in political communication: a monography, Nauka, 2008, $248 \mathrm{p}$.

[7] E.V. Budaev, Comparative political metaphorology, NTSPA, 2011.

[8] E.V. Budaev, A.P. Chudinov, Transformations of precedent text "Metaphors We Live by" in academic discourse, Voprosy Kognitivnoy Lingvistiki 1 (2017) 60-67. DOI: 10.20916/1812-3228-2017-1-60-67

[9] E.N. Luchinskaya, I.S. Karabulatova, V.I. Tkhorik, V.V. Zelenskaya, S.A. Golubtsov, New aspects of intercultural communication discourse modeling in the context of globalization and migration, Opción 34(85) (2018) 789-800

[10] O.N. Kondratieva, Metaphors in media discourse as a way of interpreting the subject area "Social networks", Questions of cognitive linguistics 2 (2019) 85-94. DOI: 10.20916/ 1812-3228-2019-2-85-94

[11] E.N. Luchinskaya, I.S. Karabulatova, V.V. Zelenskaya, S.A. Golubtsov, Characteristics of Image of the Russian Family in Modern Advertising Discourse, Astra Salvensis 11(1) (2018) 699-714.

[12] N.D. Arutyunova, Functional types of language metaphors, Izvestia of the USSR Academy of Sciences, Series of literature and language 37(4) (1978) 333-343.

[13] N.D. Arutyunova, Metaphor and discourse, Theory of metaphor, Progress, 1990.

[14] G. Lakoff, The Contemporary Theory of Metaphor, Metaphor and thought,

CambridgeUniversity Press, 1992.

[15] V.G. Gak, Metaphor: universal and specific, Metaphor in language and text, Nauka, 1988.

[16] A.N. Baranov, Descriptor theory of metaphor, Languages of Slavic culture, 2014.

[17] E.S. Kubryakova, In search of the essence of language: Cognitive research, Znak, 2012.

[18] V.P. Moskvin, Russian metaphor: classification parameters, Scientific reports of the higher school, Philological science 2 (2000) 66-74.

[19] V.P. Moskvin, Russian metaphor: an essay on semiotic theory, a monograph, 4th ed, LKI Publishing house, 2012. 
[20] V.N. Telia, Metaphorization and its role in creating a language picture of the world, the Role of the human factor in language, Language and picture of the world, Nauka, 1988.

[21] G.N. Sklyarevskaya, Metaphor in the language system, monograph, Nauka, 1993.

[22] V.K. Kharchenko, Functions of metaphor, Ed. 3E, LIBROKOM, 2009.

[23] B. Marin, D. Legros, Psycholinguistique cognitive, Lecture, comprehension et production de textes, Paris, CEDEX, 2004.

[24] A. Pascu, Mathematique, informatiqueet applications aux sciences de I'homme, La logique de la determinationd'objets, Universite de Paris-Sorbonne, Paris 1V, Ecoledoctoraleconcrptsetlangages, 2008.

[25] D. Daynovska, Analyse de quelquespreverbes et prepositions francais et bulgaresdansune perspective cognitive et formelle, These de doctorat, Universite Paris IV Sorbonne, 2008.

[26] Y. Bestgen, Representation de I'espace et du temps dans le modelesituationnelconstruit par un lecteur, Discours, 3, 2008.

[27] I.P. Savchuk, I.S. Karabulatova, S.A. Golubtsov, V.V. Zelenskaya, B.Z. Akhmetova, Language features of the legend's genre as the basis of storytelling technology in advertising discourse, Amazonia Investiga (21) (2019) 522-530, Available at: https://amazoniainvestiga.info/index.php/amazonia/arti cle/view/132.

[28] E.E. Anikin, E.V. Budaev, A.P. Chudinov, Historical Dynamics of Metaforic Systems in Russian Political Communication, Voprosy Kognitivnoy Lingvistii 3 (2015) 26-32.

[29] N.Yu. Borodulina, M.N. Makeeva, O.A. Hlavenkova, Metaphorical picture of the world economy, Questions of cognitive linguistics 3 (2019) 14-25. DOI: 10.20916/1812-3228-2019-3-14-25

[30] Linguistic encyclopedic dictionary, V.N. Yartseva (Ed.), 2nd ed., Big Russian encyclopedia, 2002.

[31] K.S. Filatov, Metaphor as a way to deploy a journalistic text, Cand. Philol. sciences, SPBU, 2015, $24 \mathrm{p}$. 